\title{
Surgery Declined
}

National Cancer Institute

\section{Source}

National Cancer Institute. Surgery Declined. NCI Thesaurus. Code C148232.

An indication that an individual was offered surgical intervention but decline to undergo surgery. 